ISSN: 2594-4827

\title{
CONTRIBUIÇÕES DE ASSISTENTES SOCIAIS PARA A FORMAÇÃO HUMANA INTEGRAL DE ESTUDANTES DA EPTNM DO IFAM ${ }^{1}$
}

\author{
Júlia Angélica de Oliveira Ataíde Ferreira ${ }^{2}$ \\ Rosa Oliveira Marins Azevedo ${ }^{3}$ \\ Vanderlei Antonio Stefanuto ${ }^{4}$
}

\section{RESUMO}

Este trabalho versa sobre uma das bases conceituais da Educação Profissional e Tecnológica - EPT, a Formação Humana Integral e, em particular, sobre a inserção dos profissionais Assistentes Sociais nesse espaço sócio ocupacional. Nesse sentido, trará três depoimentos, frutos de pesquisa empírica realizada com Assistentes Sociais de três campi do Instituto Federal de Educação, Ciência e Tecnologia do Amazonas, com a pretensão de refletir sobre as contribuições destes profissionais para a Formação Humana Integral de estudantes da Educação Profissional Técnica de Nível Médio EPTNM. Compreendeu estudo bibliográfico e documental, tendo como instrumento de informação o questionário. Os depoimentos dos Assistentes Sociais apontam para o desenvolvimento de um trabalho que busca contribuir para a formação humana integral dos sujeitos, destacando-se as principais contribuições: aporte para o desenvolvimento do senso crítico dos estudantes, objetivando uma formação cidadã; práticas voltadas ao desenvolvimento das potencialidades dos estudantes, tendo como norte sua história de vida e suas dificuldades sejam em aspectos emocionais, estruturais, culturais, políticos, sociais; promoção do entrosamento e participação da família na rotina do instituto; operacionalização de atividades como rodas de conversa, oficinas, palestras etc. sobre temas transversais, buscando despertar uma consciência crítica e reflexiva nos estudantes; orientação quanto a direitos e deveres; operacionalização de recursos necessários para a manutenção dos estudantes no instituto, garantindo o suporte material e social para o êxito escolar.

Palavras-chave: Educação profissional técnica de nível médio; Formação humana integral; Assistente Social.

\footnotetext{
${ }^{1}$ Uma versão preliminar desse texto foi apresentada no I Simpósio Amazônico em Educação Profissional e Tecnológica, promovido pelo ProfEPT/IFAM/CMC, realizado em Manaus, Amazonas, nos dias 28 e 29/11/2018.

${ }^{2}$ Estudante do Mestrado em Educação Profissional e Tecnológica do Instituto Federal de Educação, Ciência e Tecnologia do Amazonas. julia.angelica@ifam.edu.br.

${ }^{3}$ Doutora em Educação em Ciências e Matemática. Professora do Mestrado em Educação Profissional e Tecnológica do Instituto Federal de Educação, Ciência e Tecnologia do Amazonas. E-mail: rosa.azevedo@ifam.edu.br

${ }^{4}$ Doutor em Biologia Tropical e Recursos Naturais. Professor do Mestrado em Educação Profissional e Tecnológica do Instituto Federal de Educação, Ciência e Tecnologia do Amazonas. E-mail: aride@ifam.edu.br
} 


\title{
CONTRIBUTIONS OF SOCIAL ASSISTANTS FOR THE INTEGRAL HUMAN TRAINING OF STUDENTS OF THE EPTNM OF IFAM
}

\begin{abstract}
This work deals with one of the conceptual bases of the Professional and Technological Education - EPT, the Integral Human Formation and, in particular, about the insertion of the Social Welfare professionals in this occupational social space. In this sense, he will present three testimonies, fruits of an empirical research carried out with Social Assistants from three campuses of the Federal Institute of Education, Science and Technology of Amazonas, with the intention of reflecting on the contributions of these professionals to the Integral Human Education of Professional Education students Middle Level Technique - EPTNM. It comprised a bibliographical and documentary study, having as an information instrument the questionnaire. The testimonies of the Social Assistants point to the development of a work that seeks to contribute to the integral human formation of the subjects, highlighting the main contributions: contribution to the development of the critical sense of the students, aiming at a citizen training; practices aimed at the development of students' potentialities, based on their life history and their difficulties in emotional, structural, cultural, political and social aspects; promotion of family involvement and involvement in the routine of the institute; operation of activities such as talk wheels, workshops, lectures, etc. on crosscutting themes, seeking to awaken a critical and reflective awareness among students; guidance on rights and duties; necessary resources for the maintenance of students in the institute, guaranteeing the material and social support for school success.
\end{abstract}

Keywords: Professional mid-level technical education; Integral human formation; Social worker.

\section{INTRODUÇÃO}

A responsabilidade pela formação integral dos estudantes não recai apenas para o professor, todos os profissionais envolvidos na Educação Profissional Técnica de Nível Médio - EPTNMpossuem coparticipação nessa missão, destacando-se neste contexto, os profissionais de Serviço Social.

O Serviço Social é uma profissão que viabiliza os direitos sociais dos usuários, por meio de programas e políticas sociais. Na política educacional, que desempenha um papel estratégico do ponto de vista econômico, social e cultural na sociedade brasileira, a profissão é requisitada em um diversificado leque de atuação, tendo em vista que as 
múltiplas expressões da questão social, objeto de intervenção do Assistente Social, se manifestam amplamente no cotidiano escolar.

Neste trabalho, pretendemos discutir para além do trato das questões sociais latentes no âmbito educacional, especialmente no Instituto Federal de Educação Ciência e Tecnologia do Amazonas - IFAM. O objetivo é desvelar como no fazer profissional, os Assistentes Sociais visualizam sua contribuição para a formação humana integral dos estudantes da EPTNM.

Presentes em todos os campi do IFAM, os Assistentes Sociais compõem equipes multidisciplinares, com vistas a apoiar as atividades do ensino, pesquisa e extensão. Para a pesquisa foram entrevistados cinco assistentes sociais, de cinco diferentes campi do IFAM. Frente às respostas, fez-se um recorte de três, tendo em vista apresentarem-se como as que mais se aproximaram da discussão proposta.

$\mathrm{O}$ artigo está organizado em duas partes: a primeira apresenta o percurso metodológico do estudo e a segunda apresenta seus resultados e discussões. Na segunda parte, iniciamos discutindo o conceito de formação humana integral, transpassando brevemente pela própria história da educação brasileira e a quem ela serviu/serve historicamente; na sequência veremos como se deu a inserção do Serviço Social na educação brasileira, como ele se reconceituou e sua atuação na EPTNM, especificamente no IFAM; por fim, analisaremos os depoimentos dos Assistentes Sociais sobre como sua atuação profissional vem contribuindo para a formação humana integral dos estudantes deste IF.

\section{PERCURSO METODOLÓGICO}

Ouvir dos Assistentes Sociais que atuam no Instituto como se enxergam no processo de formação humana integral dos estudantes foi a instigação de origem. A pesquisa, levando-se em conta a forma de obtenção de parte dos dados, envolveu estudos bibliográfico e documental (MARCONI; LAKATOS, 2003, p.158) que consubstanciaram o aporte teórico e, posteriormente nos reportamos para o campo empírico com a análise de três depoimentos de Assistentes Sociais em três diferentes campi do IFAM. Neste contexto, o foco desta pesquisa, de cunho qualitativo será compreender e aprofundar os fenômenos, que serão explorados a partir da perspectiva 
dos sujeitos participantes, inseridos em seus ambientes naturais. (HERMÁNDEZ; COLLADO BATISTA-LUCIO, 2013, p. 376).

Para tanto, a proposta de discussão foi enviada, digitalmente, para cada um, usando-se um questionário digital estruturado, composto pela seguinte questão: A formação humana integral visa à superação da dicotomia entre trabalho manual e intelectual, que faz parte da história da Educação do país, onde aos filhos da classe operária foi destinada a formação para um ofício, mecanicista e mercantil, que promovesse perpetuação da relação de dependência econômica, cultural; e aos filhos das elites o domínio das letras, das artes, da ciência. Hoje buscamos superar isso, através de uma educação que forme o aluno em todas suas dimensões: social, cultural, técnica, humana etc. E nós? Como estamos contribuindo para essa formação? Relatem suas experiências.

A utilização da técnica de coleta de dados, através de questionário se justifica, uma vez que essa técnica de coleta de dados objetiva o conhecimento de opiniões, crenças, sentimentos, interesses, expectativas, e especificamente, como é o caso dessa investigação, registrar situações vivenciadas por um público alvo em questão (GIL, 1999 p. 128).

Ainda assim, a escolha do questionário como instrumento de coleta de dados ocorreu em vista dos seguintes aspectos, destacando-se: maior abrangência geográfica, o que era necessário devido à dificuldade em realizar visitas presenciais juntoaos Assistentes Sociais; tempo para os respondentes escreverem suas respostas; menor risco de distorção por influência da pesquisadora, que também é Assistente Social. Ressaltase que todos os profissionais lotados nos campi receberam o convite para participar, exceto as Assistentes Sociais que atuam na reitoria, porém apenas cinco responderam. Diante da problemática levantada, os profissionais, responderam de forma aberta e livre e enviaram as respostas também por via digital. Essa coleta ocorreu no mês de setembro de 2018.

\section{RESULTADOS E DISCUSSÕES}

Esta parte está organizada em três seções: a primeira trata sobre a formação humana integral na EPTMN; a segunda discute a contribuição do assistente social na 
política de educação; a terceira apresenta a percepção de Assistentes Sociais do IFAM sobre sua ação para a formação humana integral de estudantes da EPTNM.

\section{Formação Humana Integral na EPTNM}

Iniciamos a discussão conceitual sobre formaçãohumana integral fazendo um recorte histórico da Educação Profissional e Tecnológica, a fim de situar o dualismo que se pretende romper entre a educação para o trabalho manual e a educação para uma formação humana integral. A história tem mostrado a antiga prática paternalista de o Estado despender vultosa verba para custear apenas os filhos da elite a fim de perpetuar seus status econômico e social e dificultado sobremaneira a adoção de iniciativas de acesso a bens constitutivos. Dentre esses, encontra-se a Educação, que é um dos bens constitutivos que geram maior mobilidade cultural e social, e pode, com isso, impactar diretamente as estruturas sociais.

Para Vieira e Vieira (2014), a educação é um componente essencial para as reflexões sobre a reprodução e a superação das desigualdades. Eles citam as conclusões de Bourdieu e Passeron de que, não obstante sua universalidade e proposta democrática, o modelo de ensino termina por produzir desigualdades existentes na própria sociedade.

Os autores supracitados constatam que a escola seria uma instituição destinada a reproduzir o ethos do grupo hegemônico através do exercício de violência simbólica e inculcação de arbítrio cultural. E ao reproduzir esse ethos dominante, reproduz a própria sociedade e suas desigualdades.

No Brasil, a educação profissional caminhou por essa vertente da desigualdade. Ela tem a sua origem dentro de uma perspectiva assistencialista com o objetivo de "amparar os órfãos e os demais desvalidos da sorte", como denominam diversos pesquisadores da área, ou seja, de atender àqueles que não tinham condições sociais satisfatórias. Nesse sentido, buscava-se prepará-los para o exercício de um ofício, enquanto que os filhos das elites debruçavam-se no estudo das letras e das artes, perpetuando a desigualdade social existente. Para os trabalhadores destinava-se a educação elementar e de preparação para às atividades manuais e profissionalizantes, para as elites a formação literária e científica. Segundo Magalhães (2011, p. 93):

A iniciativa brasileira de formar mão-de-obra: ocorreu por decorrência do pensamento europeu proveniente do século XIX, segundo o qual, a 
sociedade se constituía de duas classes sociais opostas: burgueses e trabalhadores, que possuíam papéis diferentes e para os quais a escola deveria ser organizada de maneira particular. Nesse sentido, às classes de poder aquisitivo considerável eram reservados os estudos clássicos, o trabalho intelectual era valorizado às elites; às classes menos favorecidas cabia o trabalho manual, menos valorizado. Sacramentava-se, assim, a velha dualidade do ensino: uma escola para os pobres e uma escola para os ricos; uma escola para aqueles que vão dirigir a sociedade e uma escola para aqueles que vão servir a sociedade.

A razão de oferecer ao povo, que se aglomerava nas cidades, uma profissão, uma ocupação/ofício por meio do ensino profissional era a geração de maiores incentivos ao trabalho e mão-de-obra às indústrias que começavam a surgir no país, devido às mudanças que vinham ocorrendo na economia agrário-exportadora. O público alvo desse ensino era o considerado desprovido da riqueza e que, por conseguinte, estava à margem da sociedade e desvinculado dos setores produtivos, engrossando um grupo urbano periférico que atrapalhava o desenvolvimento do país. (KUNZER, 2009).

A separação entre escola e produção reflete, por sua vez, a divisão que se foi processando ao longo da história entre trabalho manual e trabalho intelectual. No Brasil, a educação que a burguesia concebeu e realizou sobre a base do ensino primário comum não passou, nas suas formas mais avançadas, da divisão dos homens em dois grandes campos: aquele das profissões manuais para as quais se requeria uma formação prática limitada à execução de tarefas mais ou menos delimitadas, dispensando-se o domínio dos respectivos fundamentos teóricos; e aquele das profissões intelectuais para as quais se requeria domínio teórico amplo, a fim de preparar as elites e representantes da classe dirigente para atuar nos diferentes setores da sociedade.

Ramos (2008, p. 2) aborda essa discussão, mostrando que essa dualidade educacional é reflexo da dualidade existente no próprio sistema capitalista:

Vemos, então, que a história da dualidade educacional coincide com a história da luta de classes no capitalismo. Por isto a educação permanece dividida entre aquela destinada aos que produzem a vida e a riqueza da sociedade usando sua força de trabalho e aquela destinada aos dirigentes, às elites, aos grupos e segmentos que dão orientação e direção à sociedade. Então, a marca da dualidade educacional do Brasil é, na verdade, a marca da educação moderna nas sociedades ocidentais sob o modo de produção capitalista.

Atualmente, devido um percurso travado de lutas ideológicas e políticas, a Educação Profissional e Tecnológica está orientada pela construção de um projeto 
sustentado pela formação humana integral, que supere essa dualidade entre formação específica e formação geral e que desloque o foco dos seus objetivos do mercado de trabalho para a pessoa humana. Em oposição a uma educação dual, defende-se que o conhecimento crítico-reflexivo pode proporcionar ao sujeito uma formação omnilateral. Souza Junior define o conceito de omnilateralidade como:

Conceito de grande importância para a reflexão em torno do problema da educação em Marx. Ele se refere a uma formação humana oposta à formação unilateral provocada pelo trabalho alienado, pela divisão social do trabalho, pela reificação, pelas relações burguesas estranhadas. (SOUZA JUNIOR, [entre 2008 e 2018]. s/p.)

Assim, os princípios de natureza filosófica que fundamentam a formação humana integral ou omnilateral, partem da concepção de formação humana, com base na integração de todas as dimensões da vida no processo educativo, visando à formação omnilateral dos sujeitos. Frigotto (2012) defende que formação é uma concepção que leva em conta as dimensões que constituem a especificidade do ser humano, as condições objetivas e subjetivas reais para seu pleno desenvolvimento histórico. Essas dimensões "envolvem sua vida corpórea material e seu desenvolvimento intelectual, cultural, educacional, psicossocial, afetivo, estético e lúdico" (FRIGOTTO, 2012, p. 267).

Portanto, a educação politécnica ou omnilateral é compreendida como uma educação unitária e universal destinada à superação da dualidade entre cultura geral e cultura técnica e voltada para "o domínio dos conhecimentos científicos das diferentes técnicas que caracterizam o processo de trabalho produtivo moderno" (SAVIANI, 2003, p.140 apud FRIGOTTO; CIAVATTA; RAMOS, 2005, p. 42)

Para tal, torna-se fundamental a formação de cidadãos capazes de compreender a realidade social, econômica, política, cultural e do mundo do trabalho para nela inserirse e atuar de forma ética e competente, técnica e politicamente, visando contribuir para a transformação da sociedade em função dos interesses sociais e coletivos. Ramos (2008, p. 4) afirma:

Compreender a relação indissociável entre trabalho, ciência e cultura significa compreender o trabalho como princípio educativo, o que não se confunde com o "aprender fazendo", nem é sinônimo de formar para o exercício do trabalho. Considerar o trabalho como princípio educativo equivale dizer que o ser humano é produtor de sua realidade e, por isto, se apropria dela e pode transformá-la. Equivale dizer, ainda, que nós somos sujeitos de nossa história e de nossa realidade. 
Em síntese, o trabalho é a primeira mediação entre o homem e a realidade material e social.

As bases da formação integral, portanto, baseiam-se nos princípios do trabalho compreendido como realização humana inerente ao ser (sentido ontológico) e como prática econômica (sentido histórico associado ao modo de produção); a ciência compreendida como os conhecimentos produzidos pela humanidade que possibilita o contraditório avanço das forças produtivas; e a cultura, que corresponde aos valores éticos e estéticos que orientam as normas de conduta de uma sociedade (FRIGOTTO; CIAVATTA; RAMOS, 2005; RAMOS, 2007)

Por fim, a formação integral sugere superar o ser humano dividido historicamente pela divisão social do trabalho entre a ação de executar e a ação de pensar, dirigir ou planejar. Trata-se de superar a redução da preparação para o trabalho ao seu aspecto operacional, simplificado, escoimado dos conhecimentos que estão na sua gênese científico-tecnológica e na sua apropriação histórico-social. Como formação humana, o que se busca é garantir ao adolescente, ao jovem e ao adulto trabalhador o direito a uma formação completa para a leitura do mundo e para a atuação como cidadão pertencente a um país, integrado dignamente à sua sociedade política. (CIAVATTA, 2005).

Nesse sentido, de superação dessa dicotomia, profissionais como os Assistentes Sociais podem contribuir, mesmo ausentes da sala de aula, com a formação integral dos estudantes, tendo em vista que o direito a uma formação integral, transpassa diversos aspectos do indivíduo, inclusive suas condições sociais e econômicas. A transversalidade da Assistência Social, ao manter a interface com as demais políticas, como a de Educação, é condição importante para que as políticas de atenção às necessidades sociais se firmem como direitos sociais. Sem a assistência, as políticas setoriais tendem a se elitizar e a se pautar por critérios que privilegiam a exclusão em detrimento da inclusão social.

Com essa preocupação, o Serviço Social, vem realizando várias discussões e abarcando frentes de lutas que venham a estreitar a interface da Assistência Social com a Política de Educação, especialmente a EPTNM, haja vista que com a criação/expansão dos Institutos Federais, esse passou a ser um largo espaço de atuação dos Assistentes Sociais no campo da educação. 


\section{Contribuição do Assistente Social na política de Educação}

A relação do Serviço Social com a política de Educação, que será tratada nessa seção, está intrínseca à sua própria constituição enquanto profissão. Nos meados da década de 30, a requisição pelo trabalho do Assistente Social na sociedade brasileira, ocorreu pela necessidade da classe dominante em formar técnica, intelectual e moralmente a classe trabalhadora, a partir de um padrão de escolarização necessários às condições de reprodução do capitalismo em diferentes ciclos de expansão e de crise. (ALMEIDA, 2012)

Segundo Barbosa, a ação do Serviço Social era direcionada para o ajustamento do indivíduo. Os problemas das crianças e sua família eram tratados como uma deficiência moral e de caráter por parte dos indivíduos. (BARBOSA, 2015, p.108). É somente com o movimento, denominado pelos Assistentes Sociais de Movimento de Reconceituação, que a profissão passa a caminhar para o rompimento hegemônico com o conservadorismo profissional e a traçar uma direção social estratégica que colida com a hegemonia política do grande capital. No entanto, é a partir da década de 1990, em consonância com o amadurecimento do projeto ético-político profissional, que se visualiza no Brasil um considerável aumento da inserção da categoria profissional na área da Educação.

Em documento emitido em 2014, o Conselho Federal de Serviço Social - CFESS (BRASIL, 2014), aborda a questão emergente do Serviço Social na Educação, pois apesar de ser prática histórica, na última década esse espaço sócio ocupacional tem sido mais ocupado por profissionais de Serviço Social, especialmente em âmbito federal, com a expansão dos Institutos Federais e a necessidade de se oferecer uma Política de Assistência Estudantil aos estudantes da Rede Federal.

$\mathrm{Na}$ contemporaneidade do Serviço Social, as discussões acerca da inserção do assistente social no âmbito da educação, têm ganhado mais densidade e amadurecido no sentido de dimensionar a inserção do Serviço Social não só no âmbito da escola, mas o Serviço Social no âmbito da Política de Educação. Um novo campo que tem surgido como espaço de objetivação desse trabalho é a educação profissional e tecnológica, consequência de uma significativa expansão da Rede Federal de Educação Profissional e Tecnológica no Brasil. (BRANT, 2010, p.3). 
Os Assistentes Sociais têm lutado em busca de garantir o profissional em todas as escolas brasileiras, por entender a contribuição que pode ser dada no trato das questões sociais latentes no âmbito escolar, tendo em vista que a Educação reproduz contradições da vida social e é uma política que resulta de formas históricas de enfrentamento à ordem burguesa de dominação cultural, intelectual, econômica e social.

A concepção de educação assumida pelo Serviço Social nos dias atuais é de uma educação que seja uma possibilidade para um projeto de vida que supere o determinismo social imposto aos filhos dos trabalhadores. No âmbito da EPT, uma educação que valorize uma formação que considere o ser social, os aspectos éticos, o fazer, a criação intelectual, artística, afetiva, que busque superar o individualismo, os preconceitos etc. Uma concepção que coaduna com que é preconizado nos princípios fundamentais do código de ética do Assistente Social.

I. Reconhecimento da liberdade como valor ético central e das demandas políticas a ela inerentes - autonomia, emancipação e plena expansão dos indivíduos sociais; II. Defesa intransigente dos direitos humanos e recusa do arbítrio e do autoritarismo; III. Ampliação e consolidação da cidadania, considerada tarefa primordial de toda sociedade, com vistas à garantia dos direitos civis sociais e políticos das classes trabalhadoras; (...) V. Posicionamento em favor da equidade e justiça social, que assegure universalidade de acesso aos bens e serviços relativos aos programas e políticas sociais, bem como sua gestão democrática; VI. Empenho na eliminação de todas as formas de preconceito, incentivando o respeito à diversidade, à participação de grupos socialmente discriminados e à discussão das diferenças. (BRASIL, 1993, p.1)

Nesse sentido, na política de educação, o trabalho do Serviço Social em consonância com o projeto ético e político da profissão, pressupõe a referência a uma concepção de educação emancipadora, que possibilite aos indivíduos sociais o desenvolvimento de suas potencialidades e capacidades como gênero humano (CFESS, 2014).

A interlocução da Assistência Social com a Educação, segundo Abranches (2009), objetiva colaborar para a emancipação e autonomia dos indivíduos frente situações sociais adversas e às desigualdades. Através da Educação é possível mobilizar e discutir com maior profusão sobre a conquista de direitos, a defesa da cidadania, as identidades culturais, a consciência crítica, entre outros temas. Acrescenta ainda, que a educação pode ser o instrumento para efetivar, com mais eficácia, o projeto político da 
Assistência Social, que vislumbra a cidadania plena; e a assistência social pode promover melhorias na política educacional, no que se refere aos benefícios prestados aos alunos, à contribuição política para uma formação sistêmica, ao atendimento aos problemas sociais de suas famílias e à orientação da comunidade escolar para a organização social e política. (ABRANCHES, 2009).

Dessa forma, para que o direito à Educação seja garantido qualitativamente, numa perspectiva cidadã, numa visão mais totalitária desse ser social - estudante, muitos sãos os fatores que merecem a preocupação das equipes educacionais, dentre eles destaca-se a preocupação pela permanência e êxito dos estudantes no processo educativo, tendo em vista diversos aspectos que podem fragilizar esse processo. Dentre esses fatores, podemos destacar: o acesso à instituição, dificuldades de relacionamento com a comunidade acadêmica, fatores socioeconômicos, identidade com o curso, problemas de aprendizagem, entre outros.

\section{PERCEPÇÃO DE ASSISTENTES SOCIAIS DO IFAM SOBRE SUA AÇÃO PARA A FORMAÇÃO HUMANA INTEGRAL}

Para que se retrate brevemente o trabalho do Assistente Social no IFAM e suas contribuições quanto a formação humana integral dos estudantes, sob a ótica destes profissionais, primeiramente contextualizaremoso IFAM e a inserção destes profissionais nele.

Os Institutos Federais de Educação, Ciência e Tecnologia surgiram com uma proposta de expansão do ensino técnico e tecnológico que promovem o ensino nos níveis básico, técnico e tecnológico, incluindo programas de formação e qualificação de trabalhadores, licenciaturas e cursos de pós-graduação lato e stricto sensu.

O Instituto Federal do Amazonas, tem como missão promover com excelência a Educação, Ciência e Tecnologia para o desenvolvimento sustentável da Amazônia, tendo como valores: acessibilidade e inclusão social, valorização das pessoas, cidadania, justiça social, ética e transparência, gestão participativa e democrática, inovação e empreendedorismo, respeito à diversidade, responsabilidade socioambiental e solidariedade. Conta com 15 campi, sendo três em Manaus (Manaus Centro, Manaus Distrito Industrial e Manaus Zona Leste), Coari, Lábrea, Maués, Manacapuru, Parintins, 
Presidente Figueiredo, São Gabriel da Cachoeira, Tabatinga, Humaitá, Eirunepé, Itacoatiara e Tefé proporcionando um ensino profissional a todas as regiões do Amazonas. No interior do estado, o Serviço Social conta com um profissional em cada campus, já na capital, o quantitativo dá-se desta forma: Manaus Centro - três profissionais, Manaus Zona Leste e Manaus Distrito Industrial - duas profissionais (cada). Ainda tem-se três Assistentes Sociais na reitoria, sendo duas lotadas no Departamento de Assistência Estudantil e uma na Coordenação de Benefícios e Qualidade de Vida.

No âmbito do IFAM, o profissional de Serviço Social está presente em todos os quinze campi, compondo equipes multidisciplinares. Destaca-se entre os princípios que embasam sua atuação, especialmente na Política de Assistência Estudantil:

I. Defesa da educação como um direito em compromisso com a formação humana integral do sujeito;

II. Respeito à dignidade do sujeito, sua autonomia e ao seu direito a benefícios e serviços de qualidade, bem como a convivência escolar e comunitária;

III. Igualdade de direito no acesso ao atendimento, sem discriminação de qualquer natureza;

IV. Divulgação ampla dos benefícios, serviços, programas e projetos assistenciais, bem como dos recursos oferecidos pela instituição e dos critérios para seu acesso;

V. Ampliação das condições de continuidade e apoio à formação de estudantes do IFAM;

VI. Participação da comunidade acadêmica nos processos decisórios. (IFAM, 2011)

Dentro dessa perspectiva, os profissionais lotados em diversos campus do Instituto analisaram a operacionalização do seu trabalho, com vistas à articulação entre o Projeto ético-político da profissão e à formação humana integral dos sujeitos. Para a Assistente Social 1:

A escola que atuamos como profissional é uma escola tecnicista que tem como norte uma educação técnica muitas vezes mecanizada, acrítica e pouco reflexiva, que por vezes desconsidera a dimensão social que este estudante está inserido. Logo, acredito que a grande contribuição que o Serviço Social pode ofertar para uma educação integral e humana é aproximar essas realidades, onde a escola também deve considerar o universo familiar, comunitário e social que seu aluno está inserido. Para que a escola possa desempenhar o seu 
principal papel político que é a formação cidadã de modo literal, ela deve ajudar no desenvolvimento do senso crítico dos seus estudantes, sobretudo, precisando estar em sintonia a todo contexto que eles estão submersos. Quando conectamos esses contextos podemos atuar de modo mais eficiente no sucesso escolar dos alunos, pois passamos a entender e respeitar sua diversidade, suas dificuldades sejam em aspectos emocionais, estruturais, psíquicos, culturais, políticos, sociais considerando o histórico de vida de cada um, além de incentivar a participação da família no processo sócio pedagógico da escola. De fato, é um desafio encurtar a distância desses mundos e proporcionar a formação integral e humana, mas para o desenvolvimento integral dos nossos agentes sociais (os estudantes) perpassa essa reflexão que é o papel do estado representado pela escola, a família e sociedade. É um desafio diário os educadores serem sensíveis a essa prática no âmbito das escolas técnicas, mas é necessário disputar essas narrativas e espaços para viabilizar a educação profissional técnica sem perder a essência do espaço educacional que é a cidadania.

A visão trazida neste depoimento, que considera o ensino no IFAM tecnicista, reflete o dualismo que se pretende romper, através de uma formação omnilateral. Cabe à categoria profissional a reflexão crítica sobre a educação como processo social numa perspectiva de totalidade que envolve projetos institucionais e societários em disputa, os quais podem reforçar o status quo ou insurgir-se contra o mesmo. A entrevistada acredita que o Assistente Social pode contribuir para a formação humana integral dos estudantes, quando aproxima a realidade social, familiar e escolar, onde o aluno está inserido, assim como quando busca despertar nos estudantes o senso crítico. Seguindo esse mesmo viés, a Assistente Social 2, afirma que:

O Serviço Social por ser uma profissão comprometida com seu Código de Ética e busca trabalhar para a construção do projeto ético político transformador e societário, garantindo a qualidade no serviço prestado às Instituições e aos usuários dos serviços públicos. A atuação do Assistente Social nos Institutos Federais vai muito além de executor de políticas públicas, a profissão por ter caráter político e formador de opinião trabalha junto ao alunado para despertar uma consciência crítica e reflexiva para que de fato aconteça a emancipação plena dos alunos e seus familiares, haja vista que o grupo familiar a quem pertence o aluno acaba gerando demandas ao Serviço Social do Instituto. A partir de palestras e rodas de conversa é possível dialogar e conhecer os estudantes, seus costumes e visão de mundo. Esse tipo de abordagem possibilita ao Assistente Social abertura para contribuir na formação humana dos estudantes uma vez que trabalha aspectos que abre um leque de oportunidades sobre vários assuntos, incluindo os temas transversais. O objetivo dessa abordagem propõe aos educandos perceber dentro de uma perspectiva holística que a formação deles vai muito além da técnica científica, contribui para formação nos aspectos da integralidade física, mental 
cultural, política e científico - tecnológica. A formação humana Integral é um grande desafio para os profissionais dos IFs, formar um cidadão que rompa com as barreiras da dualidade da educação histórica brasileira que vai além de execução de tarefas, é um processo que precisa do empenho de todos os profissionais da educação. Embora os Assistentes Sociais dos IFs não fazerem parte do corpo docente dos Institutos e sim dos TAEs, contribui de forma significativa para a formação dos educandos através das intervenções realizadas das mais variadas formas possibilitando o desenvolvimento da opinião crítica do alunado para os mais variados temas que o Serviço Social aborda, na tentativa de formar em sua totalidade para emancipação social plena dos jovens e adolescentes estudantes do IFAM.

Nesse depoimento a profissional busca aproximar as concepções ético-políticas da profissão com seu fazer profissional. Ela compreende a dimensão do papel do Assistente Social nos Institutos Federais para além de executor de políticas públicas, mas como um mediador para formação da consciência crítica dos estudantes nas diversas ações que executa, inclusive com as famílias. Ela aponta que romper essa dualidade histórica é desafiador e requer a cooperação de vários atores envolvidos e conclui que nas diversas atividades realizadas pelo Assistente Social, este pode contribuir para formar os estudantes mais plenamente. Por fim, a terceira Assistente Social, elenca:

O Serviço Social do campus que atuo contribui para a formação integral dos alunos trabalhando temas transversais através de projetos no âmbito da Política de Assistência Estudantil, através de palestras e ações sobre temas importantes: combate à exploração sexual de crianças e adolescentes; sensibilização sobre uso de drogas; educação em saúde (campanhas do "outubro rosa", prevenção ao HIV; gravidez na adolescência; métodos contraceptivos, etc.). Nos projetos integrais têm abordado temas como: direitos humanos; ética e cidadania; desigualdade de gênero, violência contra a mulher; insegurança alimentar; desigualdade social. Trata-se da dimensão pedagógico-interpretativa da profissão. As metodologias usadas são: palestra, roda de conversa, exibição de documentários, dinâmicas no sentido de chamar a atenção dos discentes para as temáticas. Nos atendimentos, orientamos os usuários e problematizamos os fenômenos que nos são trazidos, sempre trazendo uma visão sócio histórica para as questões.

Este depoimento revela que é possível uma intervenção crítica capaz de propor ações para além dos programas de transferência de renda, com contribuições significativas para a formação humana integral dos estudantes. No âmbito do IFAM, o Assistente Social muitas vezes é visto como o único responsável pela operacionalização 
da Política de Assistência Estudantil, limitando suas ações em apoio às atividades pedagógicas que ofereçam suporte para a permanência e êxito escolar. Porém o Assistente Social pode potencializar a construção da formação humana integral e de uma educação na perspectiva emancipatória, dentre as diversas contribuições que estes profissionais podem dá, destacam-se a elaboração e execução de programas de orientação sócio familiar, visando prevenir a evasão escolar, melhorar o desempenho e rendimento dos estudantes, e sua formação para o exercício da cidadania, como apontam as profissionais.

Nesse sentido, o Assistente Social deve participar de equipes multidisciplinares, assim como prover a elaboração de programas e projetos que visem trabalhar as questões transversais, como: uso de drogas, violência, diversidade, entre outros, estando atento às mais diversas formas de manifestação da exclusão social ou violação de direitos que possam ocorrer no Instituto.

\section{CONSIDERAÇÕES FINAIS}

A formação humana integral oferece possibilidades ao homem para pensar, ser, agir, fazer, para transformar a realidade objetiva. Ela se contrapõe ao trabalho alienado, onde o ser humano, ao invés de se libertar, estabelece uma relação de escravidão, de fadiga, de mera sobrevivência. O trabalhador reduz-se a mercadoria. Percebe-se vários entraves para operacionalização dos conceitos da formação humana integral, pois para muitos dos atores envolvidos, como afirma (FRIGOTTO, 2007, p. 1135) é mais viável a oferta de uma educação básica desarticulada da educação profissional e técnica, que se reduza ao "adestramento pragmático do mercado".

Assim, esforços e empreendimentos precisam ser feitos para incutir na cultura dos espaços educacionais a integralidade na formação do estudante. Por mais que o sistema favoreça ao individualismo, à competitividade e à mercantilização da educação, os trabalhadores da área, incluindo os Assistentes Sociais, podem articular-se, encontrando formas que promovam o debate, a formação continuada, a socialização de discussões, a integração de conteúdos, a fim de promover nos estudantes uma formação: que seja uma possibilidade para um projeto de vida que supere o determinismo social imposto aos filhos dos trabalhadores; que rompa com a dualidade entre trabalho manual e 
intelectual; que integre os conhecimentos teóricos e práticos, indo além do "aprenderfazendo"; que busque o desenvolvimento de suas potencialidades; que articule ciência, trabalho, tecnologia e cultura; que o objetivo profissionalizante não tenha uma finalidade em si, nem seja orientado pelos interesses de mercado; e que valorize uma formação que considere o ser social.

Ciavatta (2005) defende que se trata, portanto de superar a redução da preparação para o trabalho ao seu aspecto operacional, simplificado e, como formação humana, o que se busca é garantir ao adolescente, ao jovem e ao adulto trabalhador o direito a uma formação completa para a leitura do mundo e para a atuação como cidadão pertencente a um país, integrado dignamente à sua sociedade política. Formação que, nesse sentido, supõe a compreensão das relações sociais subjacentes a todos os fenômenos.

Nessa luta pela garantia da formação humana integral, o profissional de Serviço Social tem muito a contribuir, ocupando espaços e desvencilhando-se de imposições institucionais que reforçam uma prática não-reflexiva. Iamamoto (2001, p. 21) propõe que

[...] as alternativas não saem de uma suposta "cartola mágica" do Assistente Social; as possibilidades estão dadas na realidade, mas não são automaticamente transformadas em alternativas profissionais. Cabe aos profissionais apropriarem-se dessas possibilidades e, como sujeitos, desenvolvê-las transformando-as em projetos e frentes de trabalho.

Assim, as ações no cotidiano profissional devem estar comprometidas com os sujeitos, à luz do projeto de mundo que se pretende. Suas atividades técnico-operativas, que se operacionalizam nos atendimentos aos estudantes, aos seus familiares, a comunidade e aos outros profissionais, devem pautar-se na perspectiva de superação do dualismo histórico construído, a partir da afirmação de uma clara direção ético-política, articulada a um conjunto de referenciais teóricos, tendo em vista que enquanto profissão, através do seu projeto ético-político, assume compromisso com a classe trabalhadora.

$\mathrm{Na}$ análise das respostas aos questionários, tendo como norte o objetivo da pesquisa, percebeu-se os esforços dos participantes em posicionar-se em favor do rompimento de uma formação tecnicista e mercadológica, indo ao encontro de uma formação dos estudantes para o exercício da cidadania, preparação para o trabalho e para participação na sociedade. Além desses aspectos, podemos destacar as seguintes 
contribuições dos Assistente Sociais para a Formação Humana Integral de estudantes da Educação Profissional Técnica de Nível Médio - EPTNM:

- Contribuir para o desenvolvimento do senso crítico dos estudantes, objetivando uma formação cidadã;

- Trabalhar as potencialidades dos estudantes, tendo como norte sua história de vida e suas dificuldades sejam em aspectos emocionais, estruturais, psíquicos, culturais, políticos, sociais;

- Promover o entrosamento e participação da família na rotina do instituto;

- Operacionalizar atividades como rodas de conversa, oficinas, palestras etc. sobre temas transversais, buscando despertar uma consciência crítica e reflexiva nos estudantes;

- Envolver-se com demais profissionais do Instituto, professores e técnicos, para articulação de atividades multidisciplinares;

- Orientar quanto a direitos e deveres;

- Operacionalizar os recursos necessários para a manutenção dos estudantes no instituto, como: alimentação escolar, transporte escolar e demais necessidades socioeconômicas, garantindo o suporte material e social para o êxito escolar.

Por fim, a análise mostrou que essas contribuições referentes à formação do estudante são possíveis, em particular, pelo trabalho desenvolvido pelos Assistentes Sociais no IFAM, a partir do conhecimento da realidade do estudante, no âmbito familiar, comunitário e social, o que permite uma intervenção mais qualificada.

\section{REFERÊNCIAS}

ABRANCHES, M. O Trabalho do Serviço Social na Educação. In: CRESS-MG 6 Região. (Org.). Nas trilhas dos Direitos Humanos para Combater Desigualdades _ II Simpósio Mineiro de Assistentes Sociais. Belo Horizonte, 2009. Anais... Belo Horizonte: CRESS-MG, 2009. p. 149-168.

ALMEIDA, N. L. T. (Org.) de. Subsídio para a atuação de Assistente Sociais na Política de Educação. Série 3. Brasília: Anne Franco, 2012.

BARBOSA, M. Q.A demanda social pela educação e a inserção do Serviço Social na Educação brasileira. Campinas: Papel Social, 2015. 
BRANT, N. L. C. Reflexões do trabalho profissional do Assistente Social na Rede Federal de Educação Profissional e Tecnológica Brasileira. In: CRESS-MG 6 Região. (Org.). Expressões socioculturais da crise do capital e as implicações para a garantia dos direitos sociais e para o Serviço Social _ III Simpósio Mineiro de Assistentes Sociais. Belo Horizonte, 2013. Anais... Belo Horizonte: CRESS-MG, 2013. p. 1 - 13.

CFESS. Legislação e Resoluções sobre o trabalho do/a assistente social. Brasília: CFESS, 2011.

CFESS. Subsídios para atuação de assistentes sociais na Política de Educação. Série Trabalho e Projeto Profissional nas Políticas Sociais, n³3. Brasília: CFESS, 2014.

CIAVATTA, M. A formação integrada: a escola e o trabalho como lugares de memória e de identidade. In. FRIGOTTO, G.; CIAVATTA, M; RAMOS, M. (Orgs.). Ensino Médio Integrado: concepção e contradições. São Paulo: Cortez, 2005.

CÓDIGO DE ÉTICA PROFISSIONAL DO ASSISTENTE SOCIAL. Conselho Federal de Assistentes Sociais. (Lei 8.662/93). Março de 1993.

FRIGOTTO, G. Educação omnilateral. In: CALDART, R. S. et al. Dicionário da Educação do Campo. Rio de Janeiro, São Paulo: Expressão Popular, 2012.

GIL, Antônio Carlos. Métodos e técnicas de pesquisa social. 5. ed. São Paulo: Atlas, 1999. 176p.

HERNÁNDEZ-SAMPIERI, Roberto, CALLADO, Carlos; BAPTISTA-LUCIO. Metodologia de pesquisa. (trad.) Moraes, D. V. de.; 5. Ed. Porto Alegre: Penso, 2013.

INSTITUTO FEDERAL DO AMAZONAS. Política de Assistência Estudantil do IFAM, 2011. Disponível em $\leq$ http://www2.ifam.edu.br/proreitorias/ensino/proen/assistencia-estudantil/editais>. Acesso em: 22 ago. 2018.

KUNZER, N.C. O surgimento da rede federal de educação profissional nos primórdios do regime republicano brasileiro, Revista Brasileira da Educação Profissional e Tecnológica, v. 2, n. 2, 2009.

MAGALHÃES, F.P. Gêneros discursivos da esfera empresarial no ensino da educação profissional: reflexões, análises e possibilidades. Pelotas, 358f. 2011. Dissertação (Mestrado) - Pontifícia Universidade Católica de São Paulo. Universidade Católica de Pelotas.

MARCONI, M. A; LAKATOS, E. M. Fundamentos de Metodologia Científica. 5. ed. São Paulo: Atlas, 2003. 310 p. 158.

RAMOS, M. N. Possibilidades e Desafios na Organização do Currículo Integrado. In: RAMOS, Marise N. (Org.); FRIGOTTO, Gaudêncio (Org.); CIAVATTA, Maria (Org.). Ensino Médio Integrado: concepção e contradições. São Paulo: Cortez, 2005. 
RAMOS, M. N. Concepção do ensino médio integrado. Texto apresentado em seminário promovido pela Secretaria de Educação do Estado do Pará nos dias, v. 8, 2008. Disponível em <https://tecnicadmiwj.files.wordpress.com/2008/09/textoconcepcao-do-ensino-medio-integrado-marise ramos1.pdf >. Acesso em: 03 set. 2018.

SAVIANI, D. The theorectical shock of the Polytechnic. Trabalho, educação e saúde, v. 1, n. 1, p. 131- 152, 2003.

SOUZA JR. J. Omnilateralidade. Disponível em: <http://www2.ifam.edu.br/proreitorias/ensino/proen/assistencia-estudantil/editais >. Acesso em: 06 set. 2018.

VIEIRA, A. L. da C.; VIEIRA, J. J. O cenário de ação afirmativa e a desconstrução da elitização no Ensino Superior: notas para uma agenda de ação. O Social em Questão, ano XVII, no 32, p. 39-58, 2014. 